\title{
Assessment of the Supply Chain under Uncertainty: The Case of Lithium
}

\author{
Daniel Calisaya-Azpilcueta ${ }^{1, *(\mathbb{D})}$, Sebastián Herrera-Leon ${ }^{2,3}$ (), Freddy A. Lucay ${ }^{4}(\mathbb{D}$ \\ and Luis A. Cisternas ${ }^{1}$ \\ 1 Departamento de Ingeniería Química y Procesos de Minerales, Universidad de Antofagasta, \\ Antofagasta 1270300, Chile; luis.cisternas@uantof.cl \\ 2 School of Engineering Science, LUT University, P.O. Box 20, FI-53851 Lappeenranta, Finland; \\ sebastian.herrera@ucn.cl \\ 3 Departamento de Ingeniería Química, Universidad Católica del Norte, Av. Angamos 0610, \\ Antofagasta 1270709, Chile \\ 4 Escuela de Ingeniería Química, Pontificia Universidad Católica de Valparaíso, Valparaíso 2340000, Chile; \\ freddy.lucay@pucv.cl \\ * Correspondence: daniel.calisaya@uantof.cl; Tel.: +56-9-7929-1492
}

Received: 24 April 2020; Accepted: 1 July 2020; Published: 3 July 2020

\begin{abstract}
Modeling the global markets is complicated due to the existence of uncertainty in the information available. In addition, the lithium supply chain presents a complex network due to interconnections that it presents and the interdependencies among its elements. This complex supply chain has one large market, electric vehicles (EVs). EV production is increasing the global demand for lithium; in terms of the lithium supply chain, an EV requires lithium-ion batteries, and lithium-ion batteries require lithium carbonate and lithium hydroxide. Realistically, the mass balance in the global lithium supply chain involves more elements and more markets, and together with the assortment of databases in the literature, make the modeling through deterministic models difficult. Modeling the global supply chain under uncertainty could facilitate an assessment of the lithium supply chain between production and demand, and therefore could help to determine the distribution of materials for identifying the variables with the highest importance in an undersupply scenario. In the literature, deterministic models are commonly used to model the lithium supply chain but do not simultaneously consider the variation of data among databases for the lithium supply chain. This study performs stochastic modeling of the lithium supply chain by combining a material flow analysis with an uncertainty analysis and global sensitivity analysis. The combination of these methods evaluates an undersupply scenario. The stochastic model simulations allow a comparison between the known demand and the supply calculated under uncertainty, in order to identify the most important variables affecting lithium distribution. The dynamic simulations show that the most probable scenario is one where supply does not cover the increasing demand, and the stochastic modeling classifies the variables by their importance and sensibility. In conclusion, the most important variables in a scenario of EV undersupply are the lithium hydroxide produced from lithium carbonate, the lithium hydroxide produced from solid rock, and the production of traditional batteries. The global sensitivity analysis indicates that the critical variables which affect the uncertainty in EV production change with time.
\end{abstract}

Keywords: lithium; batteries; electric vehicles; supply chain; demand; uncertainty

\section{Introduction}

Lithium has become a strategic material since it plays an essential role in the development of a low-carbon economy [1]. The leading consumer of lithium is the battery industry, accounting for $65 \%$ 
of the global lithium market [2], making battery production a key process in the global lithium supply chain. Electric vehicles (EVs) cover the majority of the battery market, which has increased in recent years, growing from 25,000 tons of lithium carbonate equivalent (LCE), in 2015, to 205,000 tons of LCE, in 2025, according to the Deutsche Bank [3]. The Swiss Resource Capital reports projected growth from 25,760 tons of LCE, in 2015, to 202,920 tons of LCE, in 2025 [4]. The growth of EV participation in the battery market is apparent, but the magnitude of how much this participation has grown can vary depending on the databases used as a result of how their corresponding calculations have been completed. The use of exact data in the calculation of EV production makes the results vary depending on the database. This means that if the model starts with database A and database B, it will always obtain result $\mathrm{C}$, with $\mathrm{A}$ and $\mathrm{B}$ representing the reports in the literature and $\mathrm{C}$ being $\mathrm{EV}$ production. The EV production calculation changes only by changing the database used, and this calculation uses a deterministic model [5]. Several investigations have utilized material flow analysis (MFA) as a mass balance method to represent the transformation of matter through the lithium supply chain [6-8], and the majority of these studies have incorporated deterministic models [6,8-11]. Modeling the lithium supply chain with deterministic models limits the estimation of EV production with determined databases. There are several sources of information on the lithium supply chain, and the data vary according to the selected report and the year of its publication [12]. Furthermore, choosing the best database to model the production of EVs starting from lithium reserves is not a trivial task.

A typical network used for representing the lithium supply chain has the following three stages: (i) The resource mining stage, where lithium is present in the form of brine and solid rock; (ii) the chemical production stage, where the lithium takes the form of lithium carbonate, lithium hydroxide, lithium chloride, and lithium concentrate; and (iii) the product manufacturing stage, where lithium takes the form of the lithium contained in batteries, ceramics, lubricants, polymers, air treatment, aluminum, continuous casting powder, etc. $[3,7,8,13]$. In the lithium supply chain, it is very challenging to determine the quantity of lithium present in each stage over the years because of the complexity of the network. The historical extraction of lithium from brine and solid rock has been reported in the literature [2,14,15]. Chile, Australia, Argentina, and China provide more than 92\% of global lithium extracted from solid rock and brine [12,14]. These countries include large projects in their budgets, as well as the most significant reserves of lithium $[3,16]$. They also have a potential increase in the new projects that are expected to start shortly. For example, in Argentina, new plants, such as Olaroz, Orocobre, and Galaxy, will soon begin extracting lithium. Australia also has new projects, such as Pilbara, Altura, Mt. Marion, and Mt. Catlin. Chile and China are developing expansions in their actual plants [16]. The United States Geological Survey (USGS), Signumbox, British Broadcasting Corporation (BBC), the British Geological Survey, etc. [8,17] quantified the mass flows between the different stages of the lithium supply chain. The reported mass flows vary depending on the stage of the supply chain in the database under examination and the year of publication. Each database focuses on a specific part of the lithium supply chain. Some databases report only the quantity of the flow, but it is not possible to determine how they calculate the mass flow. This lack of transparency in the databases and the variability in the reported lithium supply stage contribute to the necessity of using several databases in one model. Using several databases in one model for calculating EV production requires a stochastic model. This kind of model uses an assortment of databases as its input, and therefore introduces uncertainty.

The uncertain production of EVs can be compared with a specific demand to determine the probability of an undersupply scenario. The fast-increasing demand for lithium-ion batteries used in electric vehicle fabrication will significantly increase demand in the battery market in the coming years [18-21]. Different scenarios of battery production could lead to an undersupply scenario [22,23]. A comparison between uncertain battery production with a specific demand supports the probability of an undersupply scenario [24].

We use several databases to model the material flow throughout the supply chain. Unlike a deterministic model where the model has fixed input, this research uses stochastic modeling by 
introducing uncertainty in the model input. The stochastic modeling of the global lithium supply chain identifies the variables that lead to a possible undersupply scenario. The model input uncertainty has two classifications, i.e., uncertainty over the country's lithium extraction and uncertainty of the mass flow between stages. This research decomposes the mass flow between the three stages in several paths. The distribution variables determine the percentage of mass that flows from the beginning to the end of each path, and each path has a distribution variable. The percentage variation in the distribution variables introduces mass flow uncertainty to the model. The limits of percentage variation depend strongly on the databases included in the model.

Given the variations in the information among databases, the objective of the present study is the use of stochastic modeling to represent the global lithium supply chain uncertainty in EV production by using a combination of three main methods, material flow analysis, uncertainty analysis, and global sensitivity analysis. Then, a comparison between the uncertain production and a specific demand determines the probability of occurrence of an EV undersupply scenario.

\section{Methodology}

Our methodology has the following six parts: a mathematical representation of the supply chain using stock and flow modeling, data collection, uncertainty analysis of historical production, uncertainty analysis for future estimations of production, a sensitivity analysis using the global sensitivity analysis (GSA) technique, and a classification of the variables using Monte Carlo filtering (MCF). First, we needed a mathematical representation of the supply chain that considered uncertainty in the distribution variables. Then, the uncertainty in the supply chain was determined, considering the uncertainty of the future production of the countries added to the uncertainty of the distribution variables. A sensitivity analysis selects the most sensitive variables involved in a supply chain. This analysis was applied to future matter distribution simulations. Finally, the most important variables within the supply chain under a possible undersupply scenario were selected using Monte Carlo filtering. Figure 1 provides a detailed graphical representation of the methodology.

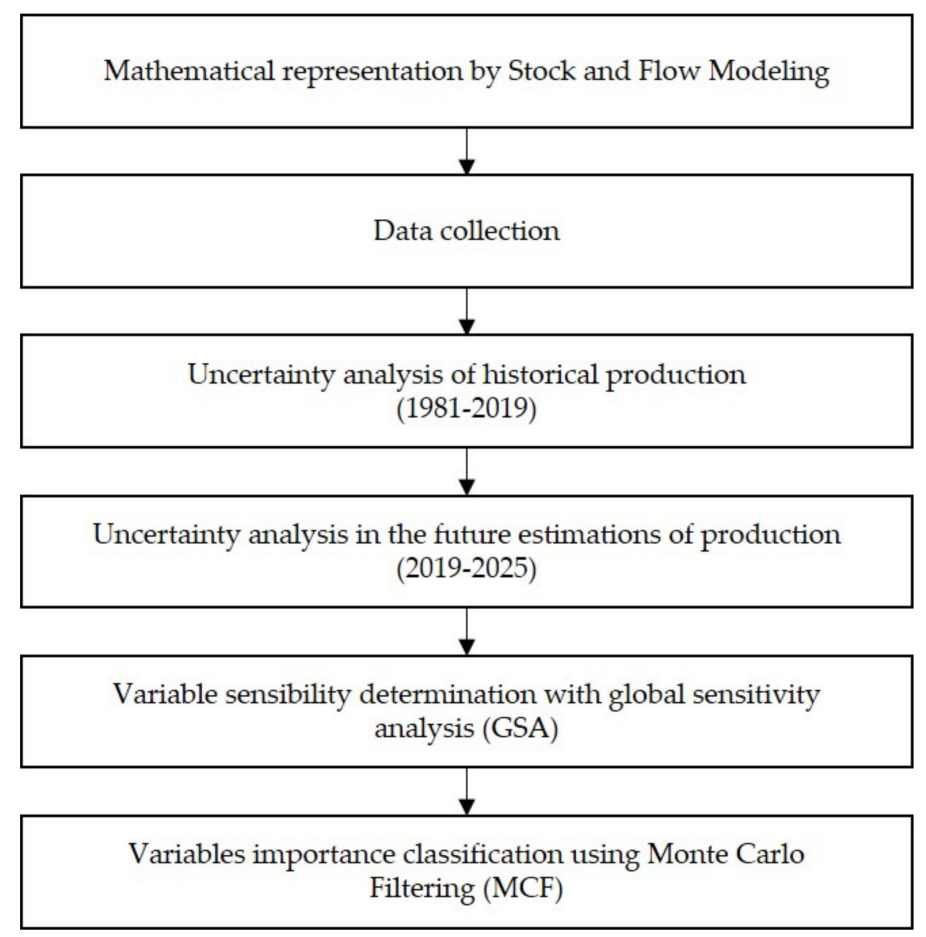

Figure 1. The methodology representing the six steps for the supply chain assessment. 


\subsection{Mathematical Representation by Stock and Flow Modeling}

\subsubsection{Conceptual Model}

The first step in the methodology involved a representation of the supply chain. The lithium supply chain was constructed based on the material flow analyses in different studies $[7,8,12]$. The following three main parts of the supply chain were determined: mining and extraction, processing, and manufacturing.

We used MFA because it is used for quantifying the stocks, flows, inputs, and losses of a resource [25]. For lithium, some studies reported the material flow using different approaches. Ziemann et al. proposed an MFA of lithium, in 2012, and separated the stages of the lithium supply chain into production, manufacture, use, and recycling waste management [10]. In 2017, Hao et al. presented an MFA of lithium in China for 2015; the stages of the supply chain in this work were resource mining, chemical production, product manufacturing, product use, and waste management [6]. Sun et al. presented a trade-linked material flow analysis in 2017. The stages in the supply chain were similar to those in the previous study but included the material distribution between different countries using 2016 databases [7]. In 2018, Sun et al. presented the global material flow between 1994 and 2015. The supply chain stages remained the same as those in the Sun et al. studies. This study used three databases to represent the material flow, providing results for 1995,2005 , and 2015 . In this past study, the lithium in the supply chain was shown to increase from 1995 to 2015 [8]. In the present study, we applied the MFA representation of Sun et al. to define the supply chain network of lithium. The stages considered were resource mining, chemical production, and product manufacturing. This modeling did not include the product use and waste management stages. We only considered values up to the product manufacturing stage because our interest focused on the possible undersupply of batteries. Some elements included in the three selected stages were minerals, basic chemicals, and products. The definitions of these elements can be found in Sun et al. $[6,8,26]$.

\subsubsection{Mathematical Model}

Asimulation material and substance flow analysis uses stock and flow modeling. Müller reviewed the application of this technique to MFA, noting that MFA was a method frequently used to assess the past, present, and future stocks and flows of metals [27]. In the present work, we conducted a dynamic simulation of the supply chain to analyze the past and future of lithium, focusing on electric vehicle production. Stock and flow modeling is the most suitable technique to simulate the lithium supply chain. Glöse stated that fewer static than dynamic simulations had been conducted [28]. One contribution of the present work is the use of a dynamic simulation combined with an uncertainty and sensitivity analysis. Suomalainen [29] used stock and flow modeling to determine dynamic modeling resource use and classified the different modeling techniques. Here, we used dynamic MFA modeling to show the evolution of the flows in the coming decades. This dynamic MFA is a mathematical representation of the lithium supply chain.

Dynamic MFA mathematically simulates the dynamic behavior of the lithium processing stages. The stock equation is given as follows [27,30]:

$$
\text { Stock }_{t}=\int_{t 0}^{t}\left(\text { inflow }_{t}-\text { outflow } \text { f }_{t}\right) d t+\text { Stock }_{t 0}
$$

where $t_{0}$ is the initial year, $t$ is the final year considered, and Stock $k_{t}$ is the mass accumulated in the

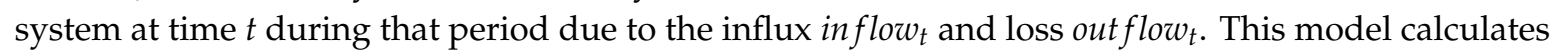
the material flow from one stage to the next. Based on this calculation, the stock depend on time and also on the stage of simulation. Equation (2) represents the stock considering both time and stage as follows:

$$
\text { Stock }_{t, i}=\int_{t 0}^{t}\left(\text { inflow }_{t, i}-\text { outflow } w_{t, i}\right) d t+\text { Stock }_{t 0, i}
$$


where $i$ represents the stage of the supply chain. The material flow starts with the production of lithium from the countries. Then, it passes through the supply chain to finally end in the production of electric vehicles. The inflow and outflow are stage and time dependent. The stage inflow corresponds to the output of the previous stage. The outflow of a stage is dependent on the stock of the stage and the variable of distribution. Equation (3) is a mathematical representation of the inflow at each stage as follows:

$$
\text { inflow }_{t, i}=\text { outflow }_{t, i-1}=\int_{\text {to }}^{t}\left(\text { Stock }_{t, i-1}\right) d t \times V D_{i-1}
$$

where $V D_{i}$ represents the variable of distribution. This variable depends only on the stage, not on time. The distribution variable represents the flow distribution between stages. Each stage has various elements, including the distribution of material between the elements of Stock $k_{t, i-1}$ and the elements of Stock $k_{t, i}$. The distribution variables are expressed in terms of percentage, defining how much material flows through its respective path.

\subsection{Data Collection}

Reports from the historical production of lithium from 1981 to 2019 comprised the data collected. Then, data on the possible increases in production were used to estimate the production from 2019 to 2025. These data were introduced to the mathematical model to perform simulations. Both periods have uncertainty in their distribution variables. The period from 2019 to 2025 entails an increase in production from the leading countries of the lithium market, i.e., Chile, Argentina, China, and Australia. These four countries have provided more than $92 \%$ of global lithium production [12,15].

One of the most commonly used databases in terms of lithium extraction is the United States Geological Survey (USGS), which annually reports the reserves of lithium and lithium extraction by country. The USGS has two kinds of reports, the Mineral Yearbook and the Mineral Commodity Summaries. The Mineral Yearbook provides detailed information about lithium production, specifying the production of the compounds in each country. The information given by these reports is available only up to 2016. The Mineral Commodity Summary reports are available up to 2020, but they only provide the total amount of extraction per country. The present research considers Mineral Commodity Summary reports up to 2020 [2]. The historical national lithium production was mainly obtained from USGS reports and complemented with other studies, such as the Macquarie report [2,31]. Different databases, such as Canaccord, Center of Energy Economics, USGS, and Macquarie, among others, broke down the elements at different stages $[2,16,31,32]$. These databases are comprehensive mainly from 2012 to 2016 because the present study considers open-source databases. More updated databases are challenging to obtain, principally because of their high price. The current stochastic modeling considers including several databases in the model, which means that including updated databases to the model could increase the uncertainty in the input of the model. Including updated databases could change the results if they are considerably different from the data used from 2012 to 2016. Due to the uncertainty in these lithium supply chain databases, future product estimations introduce the uncertainty of national production in possible new projects. The Canaccord and signumBox reports present possible future projects in different countries [16]. The last step of the methodology compares the specific demand with estimations of the supply uncertainty. Several studies have presented estimations of demand in the lithium supply chain, but these data were not open source. Here, we considered the Macquarie report data, which were used for comparisons with the estimations in our mathematical model [31].

The main contribution of this work is related to the use of uncertainty in the variables. Stochastic modeling, unlike deterministic modeling, is not dependant on one database. Therefore, new databases can be included in the model making the results change according to the uncertainty that these databases add to the model. Helton and Overkamp divided uncertainty into the following two subtypes: aleatory uncertainty which arises because the system under study can potentially behave in many different ways, and epistemic uncertainty which arises from a lack of knowledge about quantities 
that are fixed but poorly known [33]. The present work considered epistemic uncertainty due to our lack of knowledge of the variables involved in the mathematical model. One problem was the insufficient amount of data to determine the probability distribution of the variables. The characterization of epistemic uncertainty in a uniform distribution uses the principle of insufficient reasons in the absence of information to distinguish the credibility of alternatives $[24,33,34]$. To be precise, we considered all distribution variables with a continuously uniform distribution function and maximum and minimum values, where $V D_{i} \sim U(a, b)$ means that the distribution variables have a maximum value " $a$ " and a minimum value " $b$ ", as well as equal probability. For the distribution variables, the range of uncertainty was determined from the different reports in the literature.

\subsection{Uncertainty Analysis of Historical Production}

The mathematical model uses uncertainty analysis to study the uncertainty in the output variables as a result of uncertainty in the input variables. According to the related literature, several theories are available to perform this analysis, for example, the fuzzy theory and probability theory. The latter's process usually involves four steps [24]. First, the distribution functions are used to characterize the uncertainty of the input variables. Second, a sample is generated from the distribution functions, commonly using the Monte Carlo method. Third, the output variable of the model is evaluated for each element of the sample. Fourth, the results are analyzed using statistical analysis. Note that uncertainty is typically divided into stochastic and epistemic uncertainty [35,36]. The first is related to the inherent and unpredictable variation of a given system, usually due to the random nature of the input variables. The second emerges from the deficit of knowledge due to the quantities that possess fixed but poorly known values [33]. In the absence of information, it is important to distinguish the credibility of the alternatives; a uniform distribution should characterize epistemic uncertainty [24,33].

The following different methodologies exist for uncertainty assessments, each using a different approach: data uncertainty engine (DUE), error propagation equations, expert elicitation, extended peer review, inverse modeling, Monte Carlo analysis, multiple model simulation, Numerical Unit Spread Pedrigree and Assessment (NUSAP), quality assurance, scenario analysis, sensitivity analysis, stakeholder involvement, and an uncertainty matrix [37]. Two different perspectives have been used to analyze uncertainty, i.e., uncertainty in the model parameters, which is studied through sensitivity analysis, and uncertainty in the reference data, which is analyzed via uncertainty analysis. Both tools are described by Suomalainen [29]. We focused on lithium batteries for electric vehicle production as an output variable because this application of lithium has the most significant share in the lithium supply chain in the future [31,38-40]. The assessment of electric vehicle production corresponds to the uncertainty analysis. This article explores the propagation of the uncertainties from the input data to the response variable. Morgan and Henrion proposed that the error propagation method should be used only when variables have a normal distribution and the uncertainties are low. When these conditions are not satisfied, the Monte Carlo method is often used [41]. According to the principle of insufficient reason (also called the principle of indifference), a uniform distribution characterizes epistemic uncertainty in the absence of information to distinguish the credibility of the alternatives [33]. According to the literature on the lithium supply chain, variables present epistemic uncertainty due to the absence of sufficient information throughout the whole supply chain. The assessment of the parameters involved in electric vehicle production corresponds to the sensitivity analysis. In this case, the influence of individual parameters on electric vehicle production is studied by creating sensitivity indices $[42,43]$.

For historical production, uncertainty only exists in the distribution variables. The objective of the uncertainty analysis in this period is to determine the uncertainty level in the supply chain, considering uncertainty in the input of the model. To obtain representative results, the mathematical model performs 1000 simulations. 


\subsection{Uncertainty Analysis in the Future Estimations of Production}

To estimate future production, we considered the uncertainty of the distribution variables, as well as the country's production uncertainty, which increases the uncertainty in the lithium supply chain. The objective was to observe how much the uncertainty increases. In Section 2.3, we stated that the output variable being analyzed involves the production of electric vehicles. The combination of uncertainty in the distribution variables and the country's production uncertainty increases uncertainty in the production of electric vehicles.

\subsection{Variable Sensitivity Determination with Global Sensitivity Analysis (GSA)}

Sensitivity analysis involves identifying the contribution of the uncertainties of the input variables with the uncertainties of the output variables in the mathematical model. The present sensitivity analysis includes both local and global approaches. Each variable is measured, one at a time, which shows the disadvantage of depending on the choice of the evaluation point. Second, we take all input variables and examine the uncertainty range all at once. Global sensitivity analysis (GSA) involves six steps [44]. First, select the output variable of the model. Second, select the input variables of the model. Third, assign the distribution function to the input variables. Fourth, generate samples from the distribution functions. Fifth, evaluate the model using the samples. Sixth, perform the GSA and determine the effect of the uncertainty of input variables on the output variables of the studied model.

According to related theories, many methods are available to perform GSA. Among these methods, we focus on those based on the method of Sobol due to their versatility [45]. Similarly, Saltelli et al. [45] compared several approaches based on Sobol's method under distinct scenarios. The authors reported that the Sobol-Jansen method iwas the most robust. Similar results were found using performance profiles to benchmark GSA methods [46]. The Sobol-Jansen method involves calculating the first-order sensitivity index $\left(S_{j}\right)$ and the total sensitivity index $\left(S_{j}^{T}\right)$ for input variables $X_{j}$ of the mathematical model. The first is used when the aim is to determine which of the input variables is most influential in the output variable of the mathematical model. The total sensitivity index is used when the aim is to determine both the direct and indirect contributions of the input variables in the output variable of model. Note that if $S_{j}^{T} \approx 0$, then the input variable $X_{j}$ is not influential in the model output, and, consequently, this variable can take any given value, which reduces the dimensions of the model.

\subsection{Variable Importance Classification Using Monte Carlo Filtering (MCF)}

The Monte Carlo filtering (MCF) method aims to identify which input variables are most important in driving the mathematical model to perform desired and unwanted behaviors. The MCF method involves dividing the realization space into two subsets. The first set $(B)$ brings together the values of the input variables that provide the desired results of the model output. The second set $(\bar{B})$ brings together the values of the input variables that provide the unwanted results of the model output. In general, the subsets defined earlier come from the different unknown probability density functions $f_{B}\left(X_{i} / B\right)$ and $f_{\bar{B}}\left(X_{i} / \bar{B}\right)$, where $X_{i}$ is an input variable of the model. To identify the input variables that influence the model to output to $B$ or $\bar{B}$, the density functions $f_{B}\left(X_{i} / B\right)$ and $f_{\bar{B}}\left(X_{i} / \bar{B}\right)$ are compared. In this work, density functions were compared using Kolmogorov-Smirnov statistical hypothesis testing. This test employs $p$-values to determine if the input variable is important. Here, the $p$-value $P\left(D_{i} \mid H_{0}\right)$, where $P\left(D_{i} \mid H_{0}\right)$ is the probability of $D_{i}$ given the null hypothesis $H_{0}\left(f_{B}\left(X_{i} / B\right)=f_{\bar{B}}\left(X_{i} / \bar{B}\right)\right)$, $D_{i}=\sup \left\|F_{B}\left(X_{i} / B\right)-F_{\bar{B}}\left(X_{i} / \bar{B}\right)\right\|$, and $F$ is the cumulative probability function. The criterion of decision used was the following: if $p<0.01$, then the input variable is crucial; if $0.01 \leq p-$ values $\leq 0.1$, then the input variable is important; if $p$-values $\geq 0.1$, then the input variable is insignificant. According to Saltelli et al. [47], MCF cannot be performed if the number of input variables is $>20$. Our practice has shown that the fraction of set $B$ is barely larger than $5 \%$ of the total simulations when the model is large; in other words, a large model implies a lack of statistical power. 


\section{Results}

The results are divided into the following six parts: (1) the mathematical representation of the supply chain as an MFA; (2) the range of uncertainty based on data collection; (3) the uncertainty of the supply chain due to the distribution variables; (4) in addition to the uncertainty considering the distribution variables, we also provide the uncertainty considering national production; (5) the sensitivity indices are presented for future estimations of production. (6) and finally, the classification of the Monte Carlo filtering, which compares the simulations of future production with an estimation of demand, is used to present the most important variables in a scenario of undersupply. The results correspond to each part of the methodology.

\subsection{Mathematical Representation with Stock and Flow Modeling}

A stock and flow model of lithium flows was constructed. This model consists of three major segments, as shown in Figure 2. In the first stage (resource mining), we considered the production in Chile, Argentina, Australia, China, Canada, Brazil, Portugal, Zimbabwe, Namibia, Russia, and the United States. In the second stage, we studied chemical production corresponding to the processes for making butyl lithium, lithium metal, lithium chloride, lithium carbonate, lithium hydroxide, and lithium concentrate. Finally, the third stage involved products containing lithium, such as polymers, batteries, air treatment equipment, aluminum alloys, metal casting powders, ceramics and glasses, lubricant greases, and others. The connections among these stages reflect the paths in the supply chain. Figure 2 shows the 32 paths, or flows, represented as arrows.

The distribution variables determine the mass flow on each path. The sum of all the variables that come from the same element is 100\%, i.e., the distribution variables from Brine are I1 and I2 (91\% and $9 \%$, respectively). Figure 2 represents the paths with the distribution variables using just one database, which is the Center of Energy Economics in 2015 [32]. Note that every variable in the system model was calculated at each time step. For example, in this simulation, we considered a time step of one year, as the input data were based on yearly reports. The stages in Figure 2 represent resource mining in blue, chemical production in yellow, and product manufacturing in green. In the present work, we analyzed the distribution of matter from the batteries to their applications. Figure 2 also shows the distribution variables at different stages, with resource mining as $I_{n}$, chemical production as $I I_{n}$, and product manufacturing as $I I I_{n}$. Notably, the inflow of the first stage of the supply chain corresponds to the lithium production of the countries.

\subsection{Data Collection}

In our model, we only considered the distribution variables involved in lithium-ion battery application. This reduced the paths to five paths in the resource mining stage, 14 paths in the chemical production stage, and four paths in the product manufacturing stage, as shown in Figure 3. Pink arrows in the figure represent the paths that are subtracted from the stocks used in the battery industry; these paths are considered to be a loss since they cannot be used to produce lithium-ion batteries.

The upcoming sections explain the uncertainty at each stage of the supply chain. The uncertainty in future national production is due to two factors: The capacity of the production of each country is not $100 \%$, and new projects could possibly emerge. Table 1 shows the production capacity of each country, in 2015, as reported by Canaccord. We assumed that the capacity of the companies would reach $90 \%$ capacity by 2025 . Four countries represent $92 \%$ production in the resource mining stage [12]. 
Table 1. Capacity utilization rate of countries that represent $92 \%$ of the global production at the resource mining stage $[12,16]$.

\begin{tabular}{cc}
\hline Country & 2015 Production Capacity \\
\hline Argentina & $51 \%$ \\
\hline Australia & $65 \%$ \\
\hline Chile & $62 \%$ \\
\hline China & $20 \%$ \\
\hline
\end{tabular}

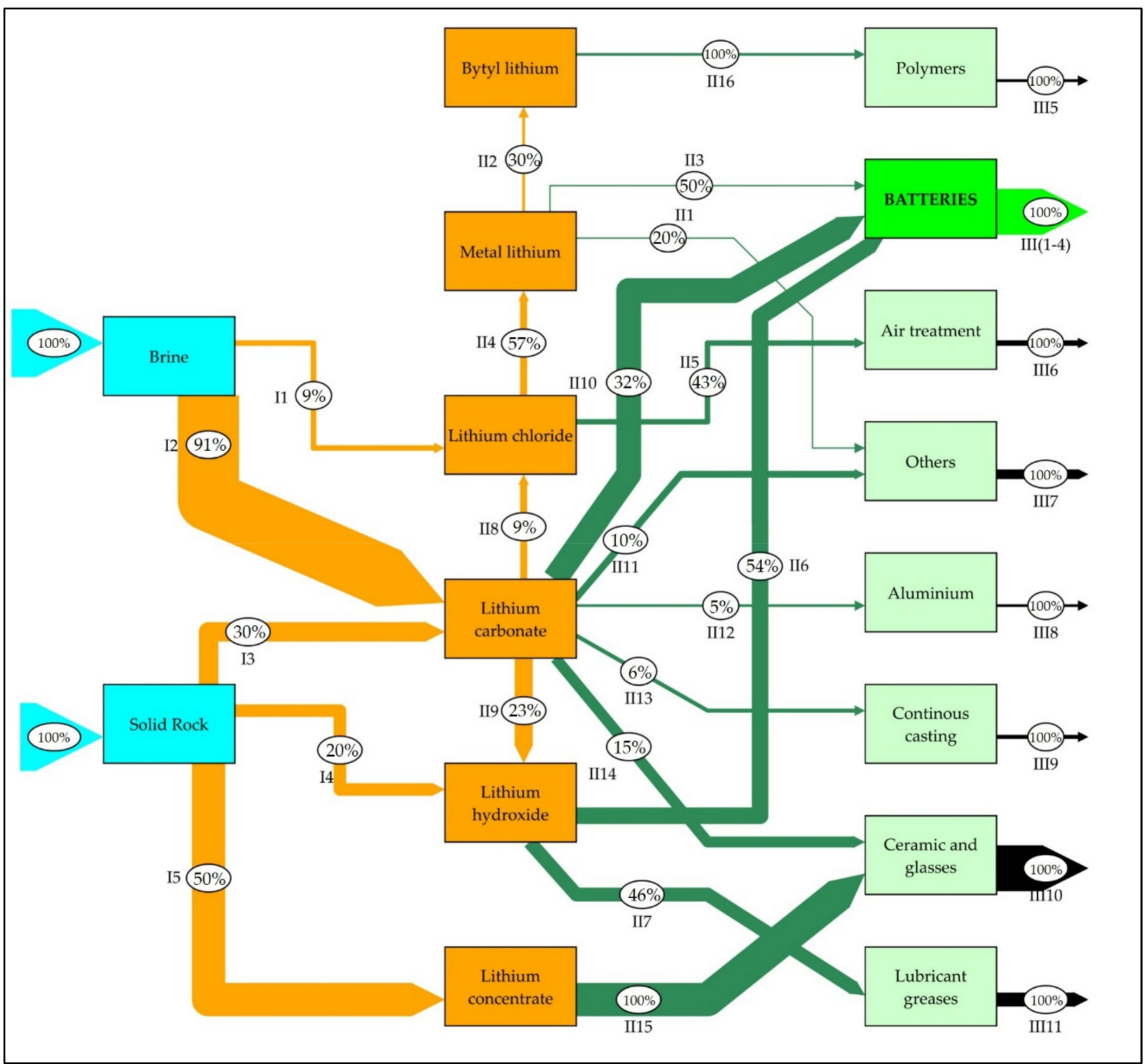

Figure 2. Material flow analysis of lithium: Resource mining is in blue, chemical production is in orange, and product manufacturing is in green. Arrows represent the paths between the supply chain stages. The ovals indicate the value of the distribution variable (\%) for each path; data from Center of Energy Economics [32]. 


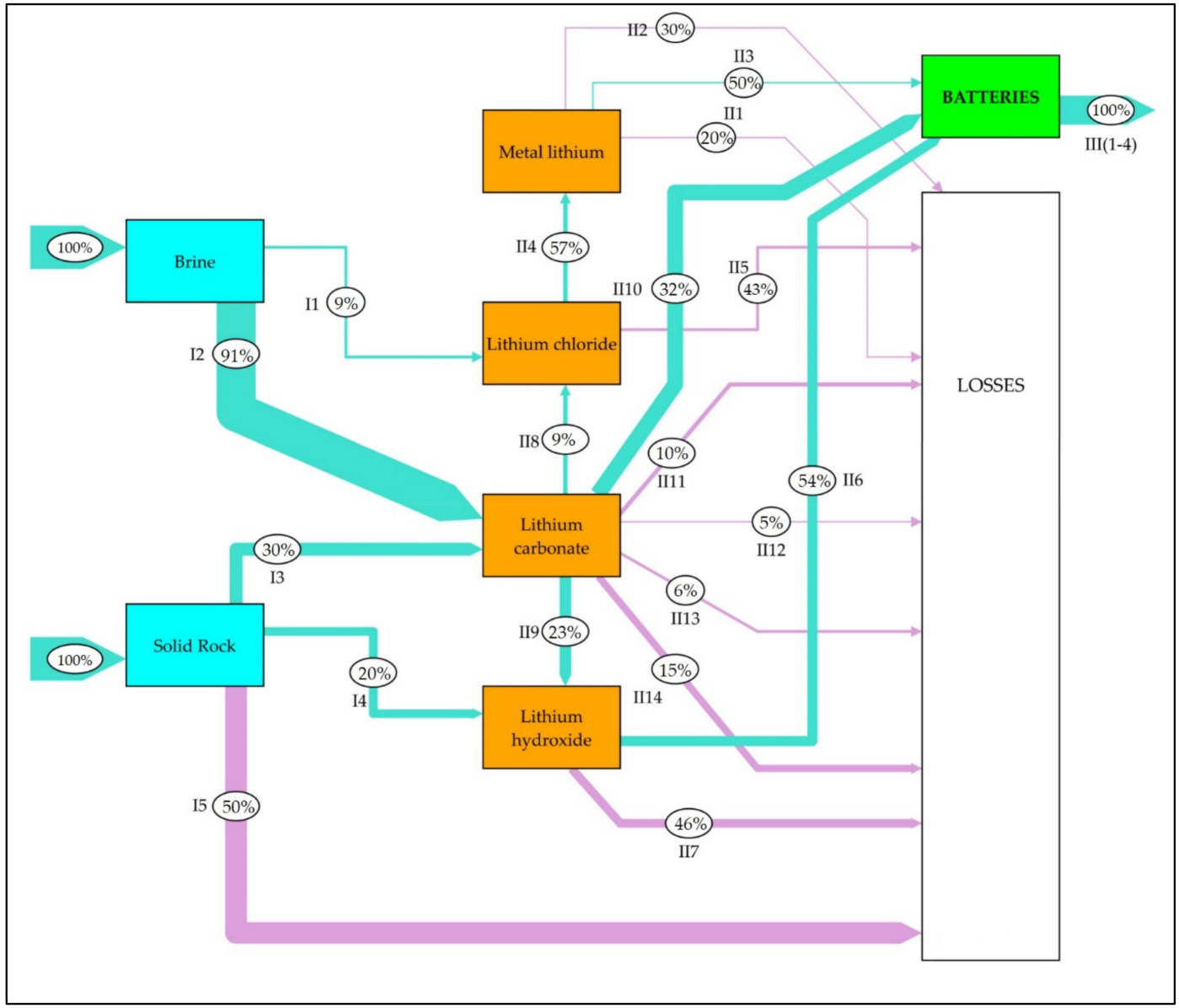

Figure 3. Material flow analysis of lithium-ion batteries, resource mining in blue, chemical production in orange, and product manufacturing in green. Blue arrows are the paths involved in lithium-ion battery applications. The purple paths represent losses. The ovals show the percentage of each variable (\%) [32].

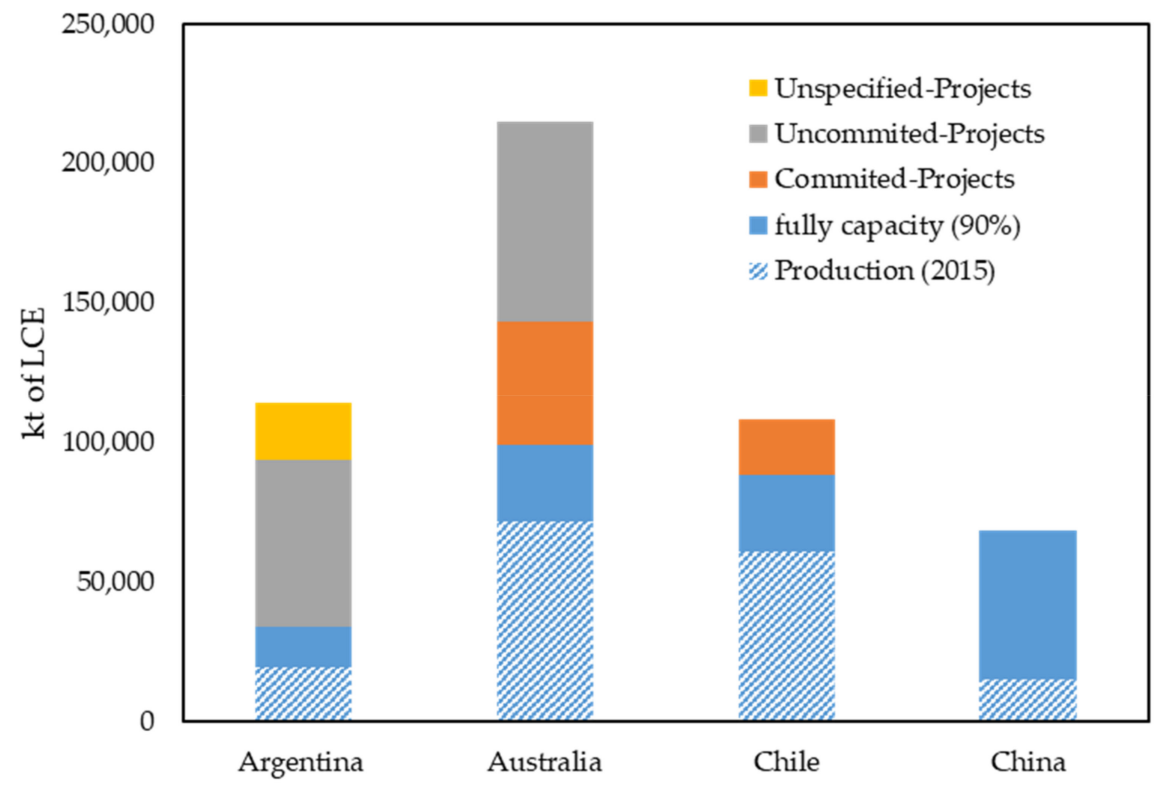

Figure 4. Unspecified project, uncommitted projects, committed projects, and the assumed full capacity of $90 \%$ for the main countries expressed as the lithium carbonate equivalent [16]. 
In terms of new projects, Figure 4 shows how the production of each country can increase. The Canaccord report considers the following three types of future projects: committed-projects in the short term, uncommitted projects in the medium term, and unspecified projects for long-term production. The report mentions $19.062 \mathrm{kt}$ of lithium carbonate equivalent (LCE) produced in Argentina, $77.368 \mathrm{kt}$ of LCE produced in Australia, $55.639 \mathrm{kt}$ of LCE produced in Chile, and 10.700 kt of LCE produced in China in 2015. This creates uncertainty in the future production of lithium [16,26,31]. Considering the full capacity and new projects, Argentina, Australia, Chile, and China have limits based on the uncertainty of their production $(113.920,225.181,108.502$, and $68.142 \mathrm{kt}$ of LCE, respectively) by 2025 .

In the first stage of the supply chain, five paths are considered (Figure 3). These paths include the amounts of lithium carbonate, lithium hydroxide, and lithium concentrate from the brine and solid rock reserves. The distribution variable uncertainty of these paths depends on time and the source of data. A report from the Deutsche Bank, in 2015, showed that the percentage of lithium carbonate makes up $50 \%$ of global lithium chemicals and that lithium hydroxide composes $20 \%$ of global lithium chemicals [3,32]. A report from Macquarie University, in 2016, broke down the lithium chemicals into $49 \%$ for lithium carbonate, $44 \%$ for lithium concentrate, $4 \%$ lithium chloride, and $2 \%$ to lithium hydroxide. [31]. The uncertainty of the distribution variables is shown in Table 2, where the uniform distribution values of minimum and maximum are presented as " $a$ " and " $b$ ", respectively.

Table 2. Maximum and minimum values for the uniform distribution in the first stage of the supply chain. The paths extend from resource mining to chemical production.

\begin{tabular}{|c|c|c|c|c|}
\hline \multirow[b]{2}{*}{ Supply Chain Stage } & \multicolumn{4}{|c|}{ Parameters of the Uniform Distribution } \\
\hline & Distribution Variable & Path & $\underset{a}{\operatorname{Min}}$ & $\underset{b}{\operatorname{Max}}$ \\
\hline \multirow{5}{*}{ Stage I } & DV-I1 & Brine to $\mathrm{LiCl}$ & $4 \%$ & $10 \%$ \\
\hline & DV-I2 & Brine to $\mathrm{Li}_{2} \mathrm{CO}_{3}$ & $53 \%$ & $91 \%$ \\
\hline & DV-I3 & Solid rock to $\mathrm{Li}_{2} \mathrm{CO}_{3}$ & $27 \%$ & $47 \%$ \\
\hline & DV-I4 & Solid rock to $\mathrm{LiOH}$ & $4 \%$ & $45 \%$ \\
\hline & DV-I5 & Solid rock to Lithium concentrate & $33 \%$ & $90 \%$ \\
\hline
\end{tabular}

There are 14 paths in the second stage of the lithium supply chain (Figure 3). These paths have distribution variables featuring uncertainty and were calculated like those in the previous stage. In this case, the variables represent the percentage of material flow between chemical production and product manufacturing. All the possible applications of lithium are presented in the product manufacture stage. The objective of the present work was to analyze battery production. This process is represented in Figure 3. There are different reports on the percentage of batteries in the global market. Grosjean, for example, reported 25\% of the battery share [48]. The Karlsruher Institut für Technologie cited a report from Roskill in 2009 that reported 20\% of the global market share for batteries [49]. The Deutsche Bank differentiates the lithium market into battery and non-battery applications, reporting that the share of batteries is $40 \%$ [3]. The USGS reported that the share of batteries is $35 \%$ [50]. The Macquarie research reported that the share of batteries is $22 \%$ [31]. The share of batteries is also the core of the present study. The rest of the applications of lithium were also considered because the material that is not used in batteries is used for other applications. Gruber reported a 19\%, 20\%, and 25\% share for 2006, 2007, and 2008, respectively [17]. Table 3 lists the values of the distribution variables in the second stage of the supply chain. 
The distribution of the batteries in the third stage of the lithium supply chain is shown in Figure 3. At this stage, among the four distribution variables, the most important is the distribution variable that determines the lithium required to produce electric vehicles. Deutsche Bank's report mentioned that the battery share distributed to electric vehicles is 34\% [3]. The Karlsruher Institut für Technologie developed an estimation where electric vehicles were dominant or pluralistic. Both scenarios suggest that electric vehicles will grow but also that the percentages of the distribution variables will change; the study proposed 23\% distribution to electric vehicles [49]. Macquarie's research reported that the percentage of electric vehicles (EVs) in 2015 was 33\% [31]. Canaccord reported that the percentage of batteries allocated to EVs in 2015 was $10 \%$ [16].

Since distribution variables have uncertainty, this model considers a normalization of the distribution variable values to guarantee $100 \%$ distribution mass by path. The uncertainty obtained in Tables 2-4 corresponds to the open-source databases studied. The minimum-maximum range in the tables can vary when including more detailed or updated databases. However, stochastic modeling has the capacity for including several databases, and therefore the model is able to calculate the uncertain mass flow of lithium through the supply chain when adding a new minimum-maximum range.

Table 3. Maximum and minimum values for the uniform distribution in the second stage of the supply chain. The paths extend from chemical production to manufacturing.

\begin{tabular}{|c|c|c|c|c|}
\hline \multirow[b]{2}{*}{ Supply Chain Stage } & \multicolumn{4}{|c|}{ Parameters of Uniform Distribution } \\
\hline & Distribution Variable & Path & $\begin{array}{c}\text { Min } \\
a\end{array}$ & $\underset{b}{\operatorname{Max}}$ \\
\hline \multirow{14}{*}{ Stage II } & DV-II1 & Metallic lithium to others & $22 \%$ & $25 \%$ \\
\hline & DV-II2 & Metallic lithium to butylithium & $56 \%$ & $70 \%$ \\
\hline & DV-II3 & Metallic lithium to batteries & $22 \%$ & $50 \%$ \\
\hline & DV-II4 & $\mathrm{LiCl}$ to lithium metallic & $30 \%$ & $64 \%$ \\
\hline & DV-II5 & $\mathrm{LiCl}$ to air treatment & $36 \%$ & $36 \%$ \\
\hline & DV-II6 & $\mathrm{LiOH}$ to batteries & $29 \%$ & $59 \%$ \\
\hline & DV-II7 & $\mathrm{LiOH}$ to lubricants & $24 \%$ & $50 \%$ \\
\hline & DV-II8 & $\mathrm{Li}_{2} \mathrm{CO}_{3}$ to $\mathrm{LiCl}$ & $7 \%$ & $10 \%$ \\
\hline & DV-II9 & $\mathrm{Li}_{2} \mathrm{CO}_{3}$ to $\mathrm{LiOH}$ & $15 \%$ & $30 \%$ \\
\hline & DV-II10 & $\mathrm{Li}_{2} \mathrm{CO}_{3}$ to batteries & $21 \%$ & $44 \%$ \\
\hline & DV-II11 & $\mathrm{Li}_{2} \mathrm{CO}_{3}$ to others & $9 \%$ & $11 \%$ \\
\hline & DV-II12 & $\mathrm{Li}_{2} \mathrm{CO}_{3}$ to aluminum & $1 \%$ & $9 \%$ \\
\hline & DV-II13 & $\mathrm{Li}_{2} \mathrm{CO}_{3}$ to continuous casting molds & $5 \%$ & $8 \%$ \\
\hline & DV-II14 & $\mathrm{Li}_{2} \mathrm{CO}_{3}$ to ceramics & $11 \%$ & $19 \%$ \\
\hline
\end{tabular}

Table 4. Maximum and minimum values for the uniform distribution in the third stage of the supply chain. The paths represent the distribution of batteries.

\begin{tabular}{ccccc}
\hline \multirow{2}{*}{ Supply Chain Stage } & \multicolumn{3}{c}{ Parameters of Uniform Distribution } \\
& Distribution Variable & Path & Min & Max \\
$\boldsymbol{a}$ & DV-III1 & Batteries to electric vehicles & $17 \%$ & $45 \%$ \\
\cline { 2 - 5 } Stage III & DV-III2 & Batteries to energy storage systems (ESS) & $1 \%$ & $5 \%$ \\
\cline { 2 - 5 } & DV-III3 & Batteries to traditional batteries & $30 \%$ & $62 \%$ \\
\cline { 2 - 5 } & DV-III4 & Batteries to two wheeler electric vehicles & $4 \%$ & $10 \%$ \\
\hline
\end{tabular}




\subsection{Uncertainty Analysis of Historical Production}

Historical production shows that uncertainty exists in the lithium supply chain due to the uncertainty of the distribution variables. The variation estimated in EV production (output variable) ranges from 15,195 to 84,058 tons of LCE. This means that the database considered has large uncertainty in the amount of lithium carbonate equivalent used to produce electric vehicles. One thousand simulations were performed to determine the uncertainty in the electric vehicle production from 2005 to 2019. Figure 5 shows the uncertainty analysis using Monte Carlo simulations. Here, the production of electric vehicles presents a normal distribution within all the years of the simulation. We noted a trend toward a lower value. This probability in Figure 5 is demonstrated by a boxplot of electric vehicle production every two years. Outliers are provided in all the graphics at the top. These values represent the low probability values for the production of electric vehicles.

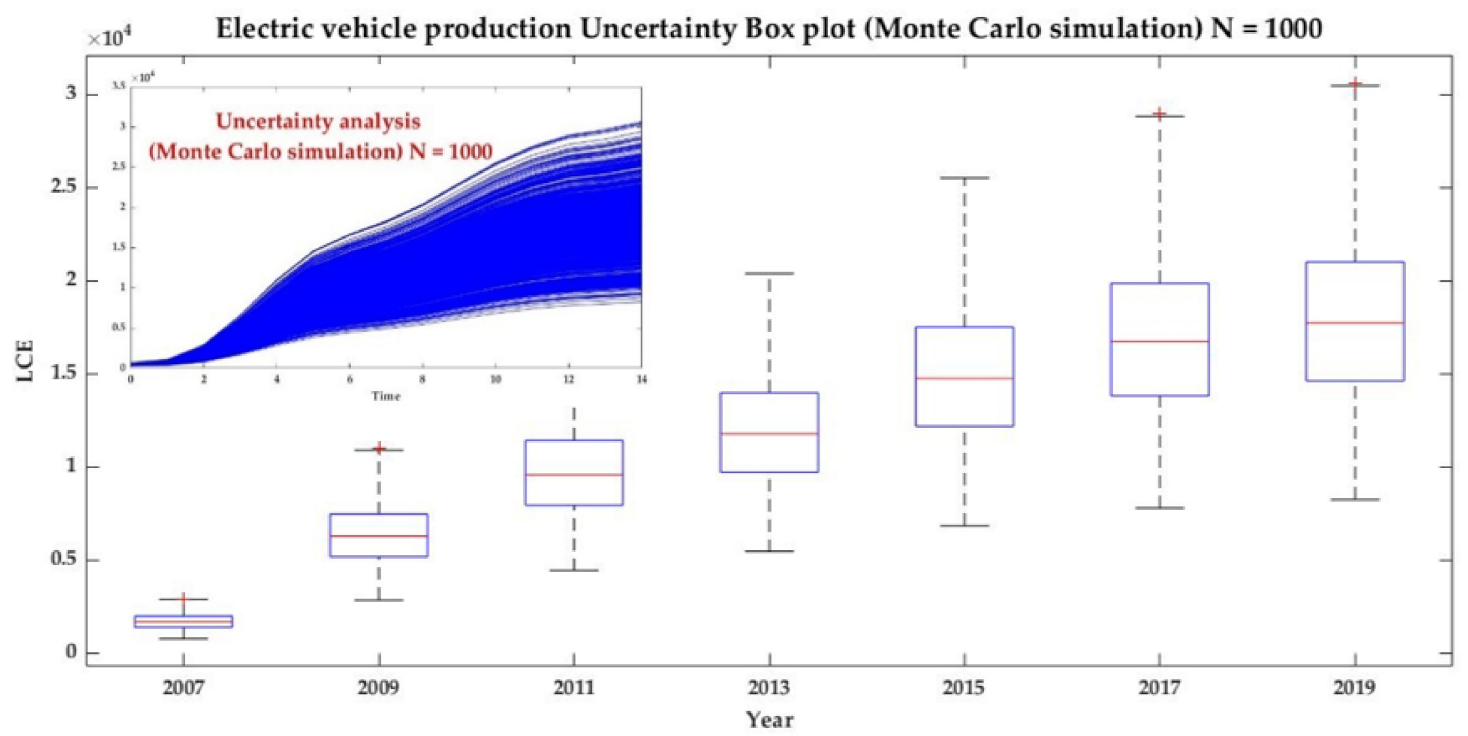

Figure 5. Uncertainty analysis of electric vehicle production from 2005 to 2019 and the probability of electric vehicle production for 2007, 2009, 2011, 2013, 2015, 2017, and 2019 expressed in terms of the lithium carbonate equivalent (LCE).

The result of the uncertainty analysis for the historical production of EV shows that uncertainty exists in the lithium supply chain when considering the uncertainty of the distribution variables within it. The objective of this analysis was to demonstrate the existence of uncertainty in the lithium supply chain but not to compare the amount of EVs produced until 2019. This comparison is conducted in the last part of the methodology along with the estimation of future production.

\subsection{Uncertainty Analysis for the Future Estimations of Production}

We added the uncertainty of national production to the uncertainty analysis of the future production of EVs. The uncertainty analysis in the future instance shows that the future uncertainty is greater than that in historical instances. We performed 10,000 simulations to obtain representative results. Figure 6 shows the uncertainty of electric vehicle production in the future. Similar to historical production, the boxplot shows outliers at the top of the graphics, which indicates that this is a less probable scenario. 

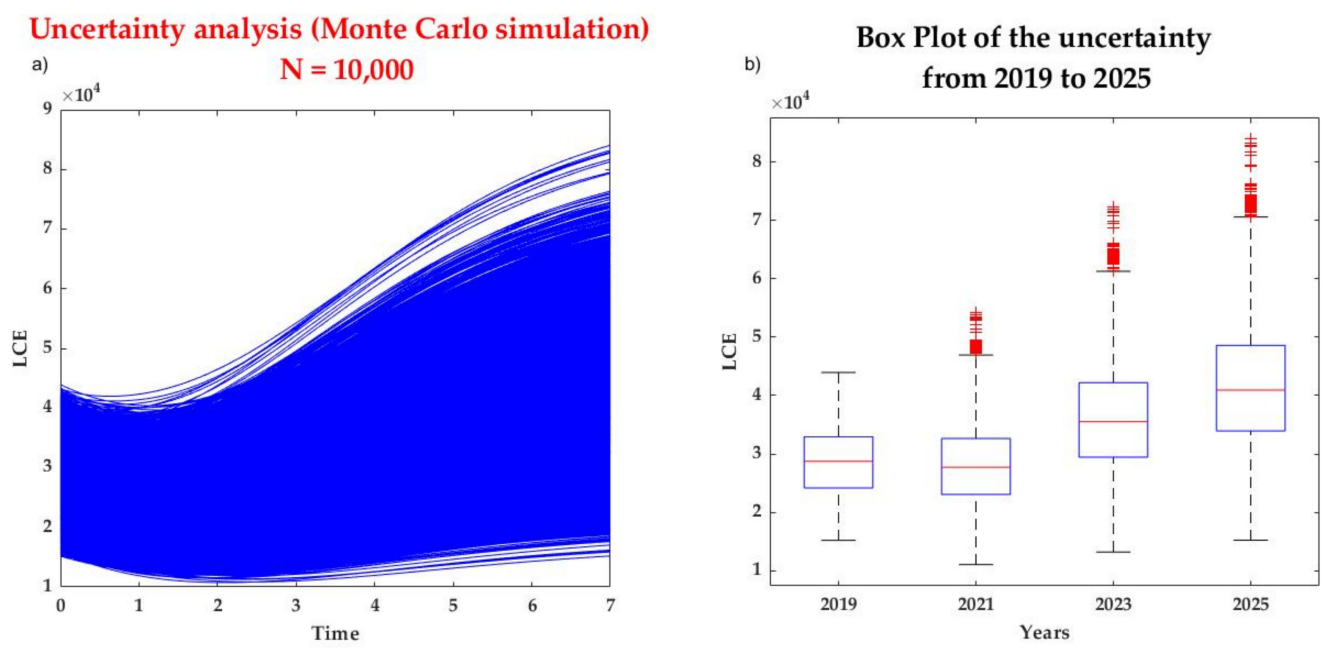

Figure 6. (a) Uncertainty analysis of electric vehicle production from 2019 to 2025; (b) The probability of electric vehicle production for 2019, 2021, 2023, and 2025 expressed in terms of the lithium carbonate equivalent (LCE).

\subsection{Determination of the Most Sensitive Variables with GSA}

Global sensitivity analysis obtains sensitivity indices from the simulation of future production. The sensitivity analysis shows that the sensitivity indices will change over time due to the dynamic nature of the simulation. The variables that represent $98 \%$ of the total uncertainty in the first year are not the same as those in the last year. Figure 7 shows the sensitivity indices and how they vary according to time.
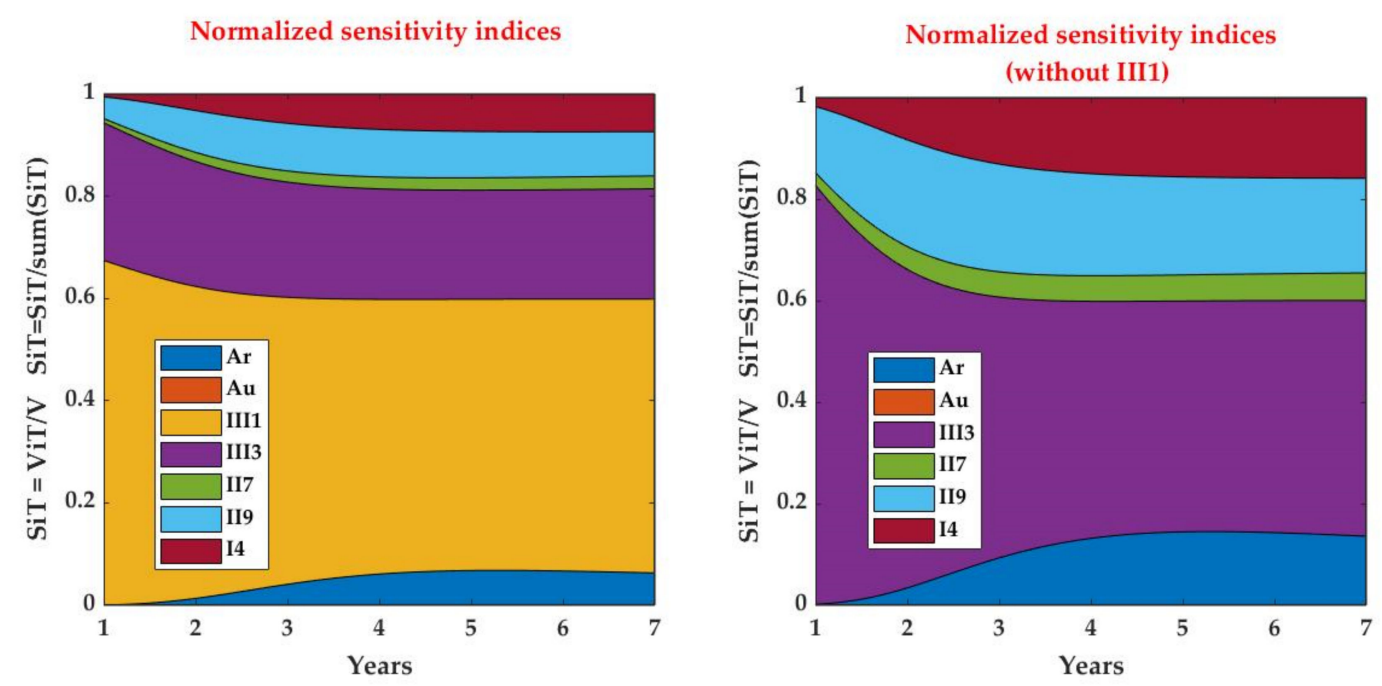

Figure 7. Normalized sensitivity indices during the period from 2019 to 2025 with the distribution of EV production (III1) and without III1.

To visualize this change, a comparison of the sensitivity indices in 2019, 2022, and 2025 is shown in Figure 8. Notably, III1 has a strong influence from the beginning of the simulations. Over time, its importance decreases until 2025. 

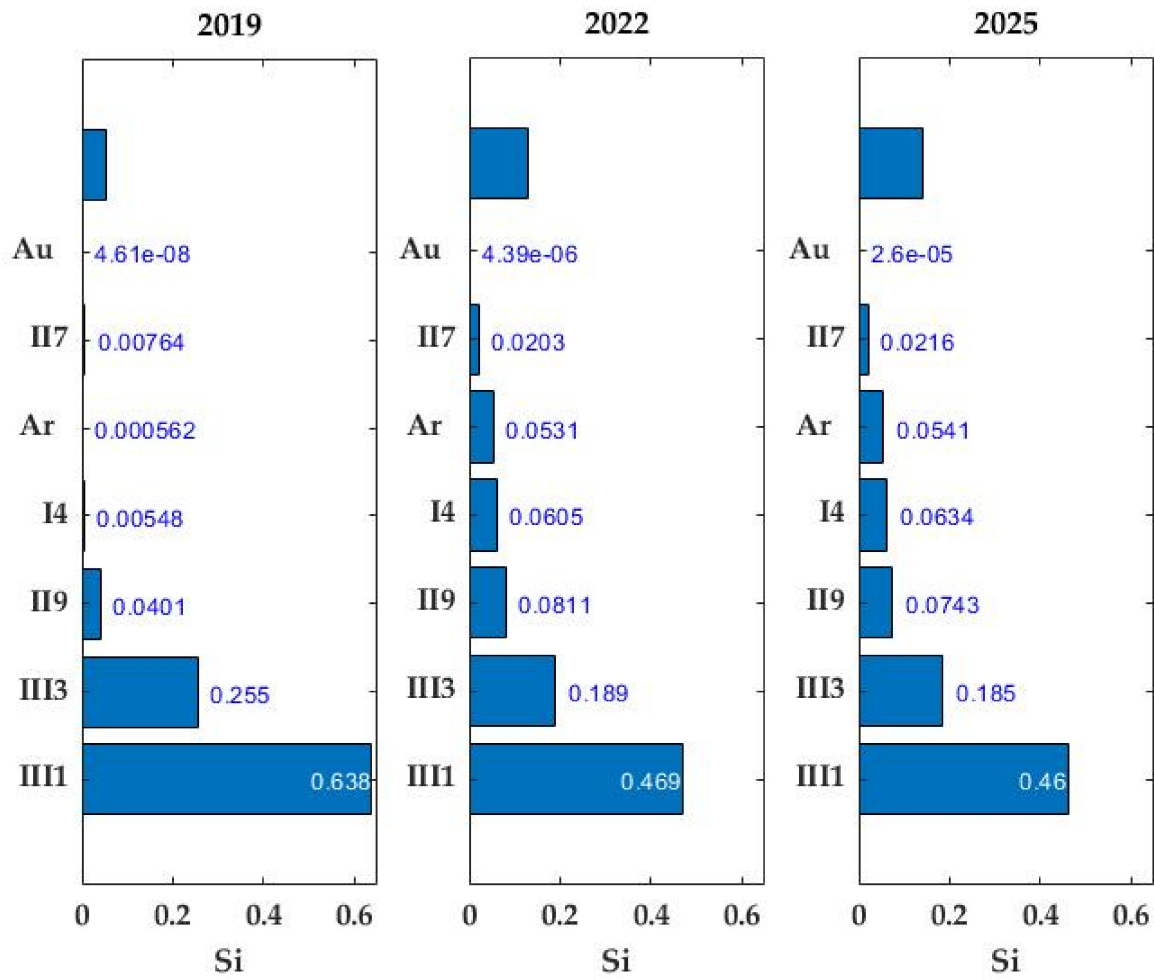

Figure 8. Sensitivity indices change over time in 2019, 2022, and 2025.

From the results of the sensitivity analysis, seven variables were selected. These variables represent $98 \%$ of the uncertainty in the future production of electric vehicles. Table 5 lists the variables selected from the analysis. Two national productions were considered along with five distribution variables. Australia and Argentina were relevant because they have the most projects proposed in the future. III1 is expected to be important because it is the variable that determines the number of EVs produced in the battery market. The distribution from batteries to traditional batteries is important because, in the future, a lower percentage of traditional batteries and a higher percentage of electric vehicles should be produced (III3). The importance of lithium hydroxide for electric vehicles is represented by variables which include the distribution from lithium hydroxide to lubricants (II7), the distribution of material from lithium carbonate to lithium hydroxide (II9), and the distribution from pegmatite to lithium hydroxide (I4). These results are contrasted with the Monte Carlo filtering.

Table 5. Selected variables with the greatest relevance to the future production of electric vehicles.

\begin{tabular}{cr}
\hline Variables with Uncertainty & Description \\
\hline III1 & Distribution from batteries to electric vehicles \\
\hline $\mathrm{Au}$ & The Australian production of lithium \\
\hline III3 & Distribution from batteries to traditional batteries \\
\hline II9 & Distribution from lithium carbonate to lithium hydroxide \\
\hline II7 & Distribution from lithium hydroxide to lubricants \\
\hline Ar & Argentinian production of lithium \\
\hline I4 & Distribution from pegmatite to lithium hydroxide \\
\hline
\end{tabular}

\subsection{Selection of the Most Important Variables Using MCF}

The objective of this research was to determine the importance of the variables that could yield an undersupply in the production of electric vehicles. A case study was considered, where a report 
of demand from Macquarie University was compared with the estimated production [31]. Note that little information exists in the literature about the dynamic demand of electric vehicles, which is why the Macquarie report was used to identify which of the variables are important for an undersupply scenario. Figure 9 shows the comparison of the results from the simulation versus those of the demand described by Macquarie.

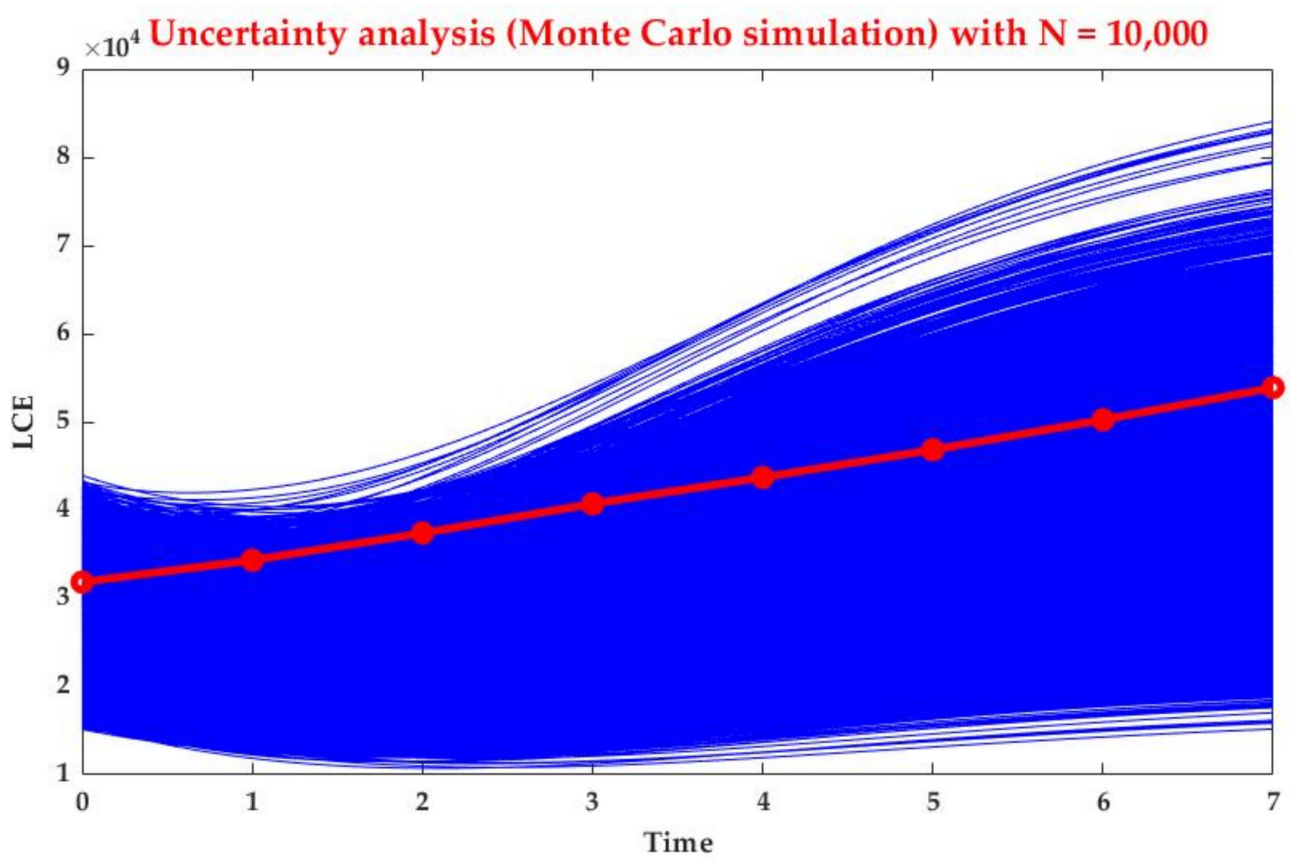

Figure 9. Electric vehicle production uncertainty vs. the reported demand from Macquarie [31] from 2019 to 2025.

The Monte Carlo filtering technique (MCF) identifies which of the variables are critical for the possible undersupply. The results obtained from both the sensitivity analysis and Monte Carlo filtering agree with each other. The MCF technique classified the variables according to their effect in a likely undersupply scenario. As with the sensitivity analysis, the analysis showed that the results changed over time. For MCF, the three classifications are crucial, important, and insignificant. Table 6 shows the ten most relevant variables for every two years of the simulation.

Table 6. Variable classification with Monte Carlo filtering.

\begin{tabular}{cccccc}
\hline Variable & \multicolumn{5}{c}{ Year } \\
\cline { 2 - 5 } & $\mathbf{2 0 1 7}$ & $\mathbf{2 0 1 9}$ & $\mathbf{2 0 2 1}$ & $\mathbf{2 0 2 3}$ & $\mathbf{2 0 2 5}$ \\
\hline III1 & crucial & crucial & crucial & crucial & important \\
\hline Aust_EV & insignificant & insignificant & insignificant & insignificant & insignificant \\
\hline $\begin{array}{c}\text { III3 } \\
\text { Batt_Tbatt }\end{array}$ & crucial & crucial & crucial & crucial & crucial \\
\hline $\begin{array}{c}\text { II9 } \\
\text { LCE_LiOH }\end{array}$ & crucial & crucial & important & important & important \\
\hline $\begin{array}{c}\text { II7 } \\
\text { LiOH_Lub }\end{array}$ & important & crucial & crucial & important & insignificant \\
\hline Argentina & insignificant & crucial & crucial & important & insignificant \\
\hline $\begin{array}{c}\text { I4 } \\
\text { Solid Rock_LiOH }\end{array}$ & important & crucial & crucial & important & crucial \\
\hline
\end{tabular}


This classification considers ten variables every year. The variable classification changes per year are based on their relevance. Among all the variables, the following three variables were always considered to be crucial: the distribution of EV production (III1), the distribution of the material from batteries to traditional batteries (III3), and the distribution of material from lithium carbonate to lithium hydroxide (II9). As per Section 2.6, the simulations classify the variables considering an undersupply scenario. Figure 10 represents the classification of the 10,000 simulations using the crucial variables, where NB represents the EV undersupply scenario. This NB group features simulations where supply is lower than specific demand. The upper figure shows the classification in 2021, and the lower figure shows the classification in 2025. The number of simulations that fit in the NB group in 2025 is larger than that in 2021.

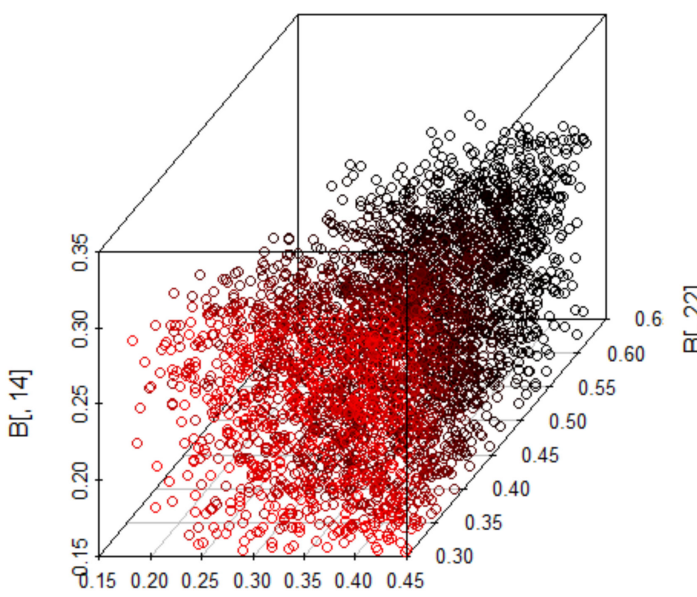

$\mathrm{B}[, 20]$

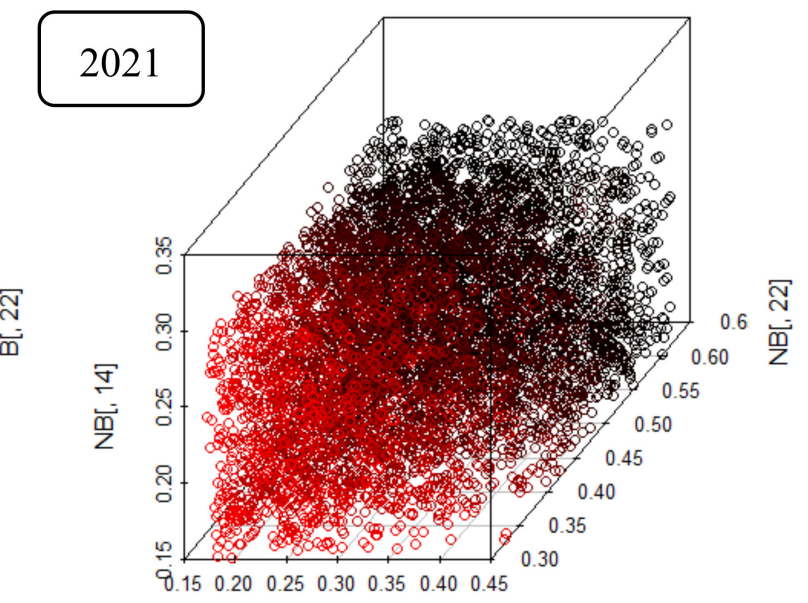

NB[, 20]

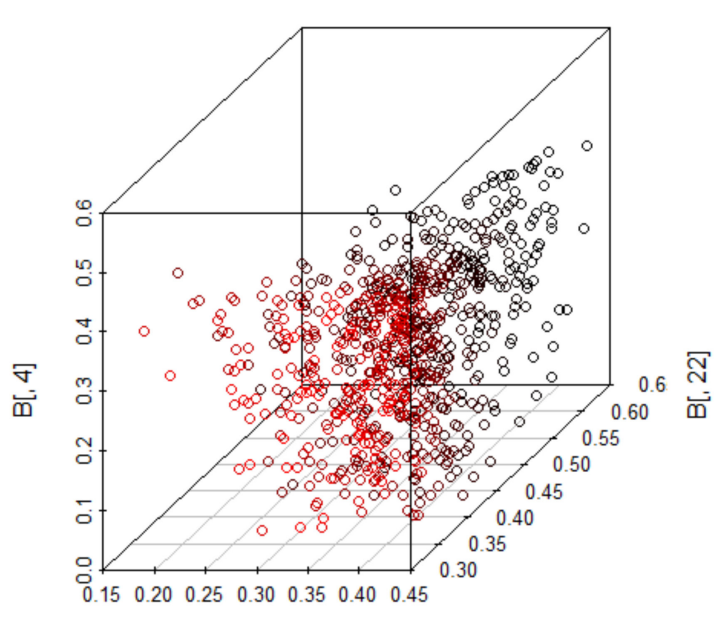

$\mathrm{B}[, 20]$

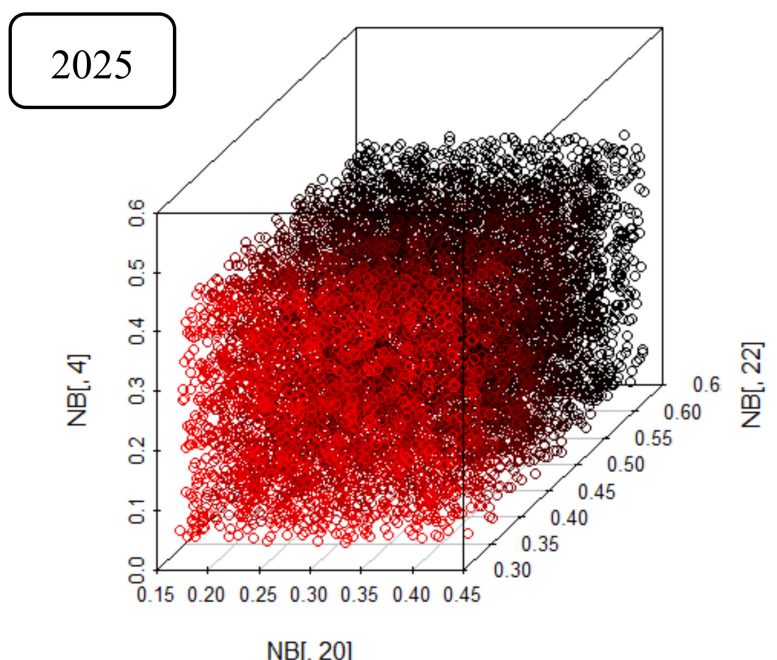

NB[, 20]

Figure 10. Regionalization of variables III1, the distribution of the material from batteries to traditional batteries (III3), and the distribution of material from lithium carbonate to lithium hydroxide (II9) from the simulations for 2021 and 2025.

\section{Discussion}

The lithium supply chain was modeled by introducing uncertainty into the material flow, unlike other material flow analyses in the literature. This study model used open-source documentation to include uncertainty in electric vehicle production. We compared the production uncertainty and 
demand from 2019 to 2025 , which showed that the undersupply scenario is more probable in 2025 than in 2021, as presented in Figure 10. Other studies have estimated the supply versus the demand [49], but the present work interpreted the supply using uncertainty. The main contribution of our research is the use of an analysis of the lithium supply chain with uncertainty to discover the sensitivity and importance of the main variables that lead to an undersupply scenario. The results from Sections 3.1-3.4 demonstrate that considerable uncertainty exists in the EV production calculated using open source databases. The applied methodology classifies the variables under uncertainty in terms of their sensitivity and importance. The sensitivity indicates the impact of the input variables (distribution variables and country's production) on the output variable (electric vehicle production). Note that this model uses sensitivity indices to quantify global sensitivity and uses Monte Carlo filtering to quantify the importance of the variables in a possible undersupply scenario [47].

Figure 11 compares the importance and sensibility of the variables from 2021 to 2025. MCF determines the critical variables in a process within a specific period. The results from Sections 3.5 and 3.6 were ultimately combined to select the variables. The importance (blue dots) of variables is related to the effect of the variables in an undersupply scenario. The sensibility (bar charts) is associated with the impact of the variables on the output variable, which is EV production in this case. The sensitivity indices represent the supply of lithium, whereas the importance compares this supply with a specific demand to determine the undersupply scenario. For the sensitivity indices, one variable has a much larger value than the rest of the variables, i.e., the flow from batteries to electric vehicles. This variable represents the output variable of the model; consequently, its sensitivity index is always higher than the rest of the variables. Figure 11 depicts the rest of the variables' sensitivity indices from 0 to 0.2 to observe how they change over the years. The variable that most drastically changed its sensitivity index was the production of Australia, which increased rapidly and made the production of electric vehicles sensitive to this variable. The production of traditional batteries affects the production of EVs because both of them use batteries as a source. The following variables experience minimum variation in their sensitivity indices: the production of Argentina, the lithium hydroxide produced from solid rock, the lithium hydroxide produced from lithium carbonate, and the lubricants produced from lithium hydroxide. This absence of variation means that these indices affect the output variable but do not change over the years. The present work expects that these sensitivity indices will continue at the same rate in the following years.

2021

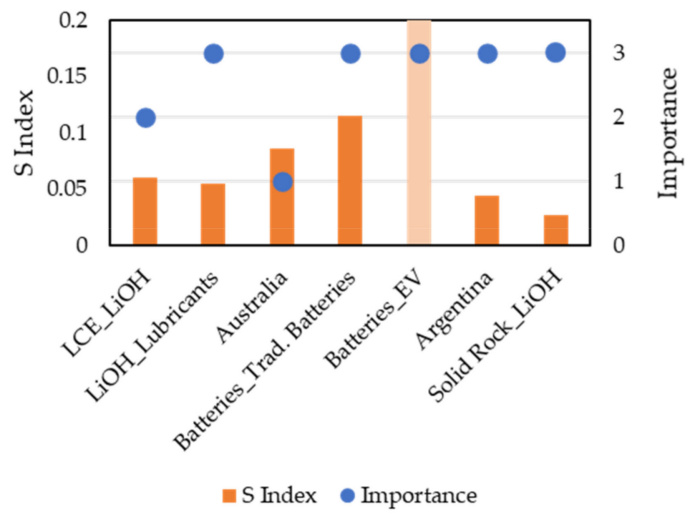

2025

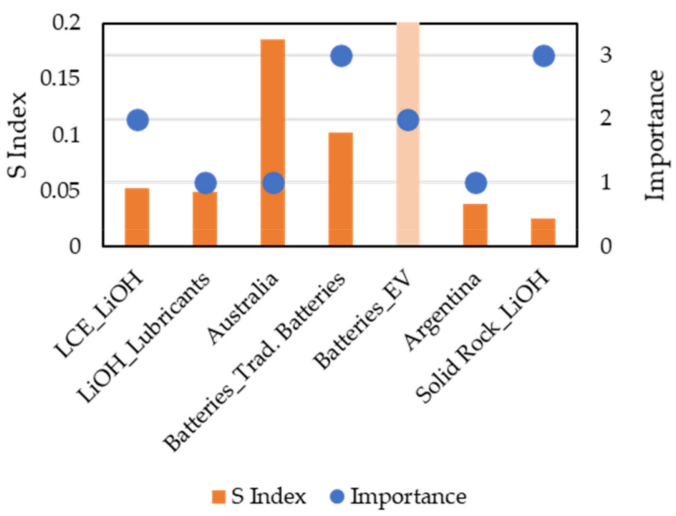

Figure 11. Sensitivity vs. importance in electric vehicle production in 2021 and 2025.

Moreover, on the one hand, Figure 11 shows the importance of the variables that lead to an undersupply scenario. This importance is assessed on a scale of insignificant (1), important (2), and crucial (3). Both the production of traditional batteries and the production of lithium hydroxide from solid rock have crucial importance in a future undersupply scenario. The lithium hydroxide converted from lithium carbonate is important in a future undersupply scenario. Indeed, this variable 
could lead to an undersupply scenario but not with the same importance as the two variables mentioned above. The production of lithium hydroxide from lithium carbonate maintains its importance over the years. This means that these variables will lead to a future undersupply scenario independent of the material flow.

On the other hand, some variables decrease their importance over the years, i.e., EV production importance decreases from crucial to important between 2021 and 2025. The lithium hydroxide used in the production of lubricants and Argentinian production experience a drastic change from crucial to insignificant over time. Australian production maintains its insignificant importance for an undersupply scenario in the future.

\section{Conclusions and Future Recommendations}

In conclusion, stochastic modeling represents the global lithium supply chain under uncertainty and classifies the variables in the global lithium EV production in terms of importance and sensitivity. The importance and the sensitivity of each variable with uncertainty can vary with time; some variables have high importance or have high sensitivity index at the beginning, and then they decrease, and vice verse. A variable with a high sensitivity index at a given time, is not necessarily crucial to an undersupply scenario, i.e., EV production is the variable with the highest sensitivity index at the beginning, but its importance decreases over the years. The comparison of supply versus specific demand (calculated under uncertainty) showed that lithium hydroxide produced from lithium carbonate, lithium hydroxide produced from solid rock, and the production of traditional batteries are important and crucial variables that do not change over time. The production of traditional batteries is a critical variable in which uncertainty varies the EV production because it directly affects the EV production. Another critical variable, in an undersupply scenario, is the production of lithium hydroxide, which complements the variable of the lithium hydroxide produced from lithium carbonate. In this case, lithium hydroxide production is crucial to the EV production undersupply scenario.

Future research could consider more detailed sources of information, including not only uncertainty in the supply but also in the demand for lithium. Long-term lithium supply and demand could include uncertainty determined via the logistic, Richards, and Gompertz models [51].

Author Contributions: Conceptualization, D.C.-A. and L.A.C.; methodology and research, D.C.-A., S.H.-L. and F.A.L.; writing-original draft preparation, D.C.-A. and S.H.-L.; development of algorithms and simulations, D.C.-A. and F.A.L.; writing-review and editing, D.C.-A. and L.A.C.; project administration and funding acquisition, L.A.C. All authors have read and agreed to the published version of the manuscript.

Funding: This research was funded by Agencia Nacional de Investigacion y Desarrollo (ANID), Fondecyt program grant number 1180826.

Conflicts of Interest: The authors declare no conflict of interest.

\section{References}

1. De Koning, A.; Kleijn, R.; Huppes, G.; Sprecher, B.; van Engelen, G.; Tukker, A. Metal supply constraints for a low-carbon economy? Resour. Conserv. Recycl. 2018, 129, 202-208. [CrossRef]

2. Jaskula, B. USGS Science for a Changing World. Available online: https://www.usgs.gov/centers/nmic/ lithium-statistics-and-information (accessed on 1 April 2020).

3. Hocking, M.; Kan, J.; Young, P.; Terry, C.; Begleiter, D. Lithium 101; Deutsche Bank Markets Research: Frankfurt, Germany, 2016.

4. Staiger, J.; Roedel, T. Lithium Report 2018; Swiss Resource Capital: Herisau, Switzerland, 2018; Volume 67.

5. Dalen, P. Understanding the Differences Between Deterministic and Stochastic Models. Available online: https://www.linkedin.com/pulse/understanding-differences-between-deterministic-stochastic-paul-dalen (accessed on 3 July 2020).

6. Hao, H.; Liu, Z.; Zhao, F.; Geng, Y.; Sarkis, J. Material flow analysis of lithium in China. Resour. Policy 2017, 51, 100-106. [CrossRef] 
7. Sun, X.; Hao, H.; Zhao, F.; Liu, Z. Tracing global lithium flow: A trade-linked material flow analysis. Resour. Conserv. Recycl. 2017, 124, 50-61. [CrossRef]

8. Sun, X.; Hao, H.; Zhao, F.; Liu, Z. Global Lithium Flow 1994-2015: Implications for Improving Resource Efficiency and Security. Environ. Sci. Technol. 2018, 52, 2827-2834. [CrossRef] [PubMed]

9. Kim, H.; Jang, Y.; Hwang, Y.; Ko, Y.; Yun, H. End-of-life batteries management and material flow analysis in South Korea. Front. Environ. Sci. Eng. 2018, 12, 3. [CrossRef]

10. Ziemann, S.; Weil, M.; Schebek, L. Tracing the fate of lithium-The development of a material flow model. Resour. Conserv. Recycl. 2012, 63, 26-34. [CrossRef]

11. Chang, T.C.; You, S.J.; Yu, B.S.; Yao, K.F. A material flow of lithium batteries in Taiwan. J. Hazard. Mater. 2009, 163, 910-915. [CrossRef] [PubMed]

12. Sun, X.; Hao, H.; Hartmann, P.; Liu, Z.; Zhao, F. Supply risks of lithium-ion battery materials: An entire supply chain estimation. Mater. Today Energy 2019, 14, 100347. [CrossRef]

13. Speirs, J.; Contestabile, M. The Future of Lithium Availability for Electric Vehicle Batteries. In Behaviour of Lithium-Ion Batteries in Electric Vehicles; Springer: Berlin, Germany, 2018; pp. 35-57.

14. Brown, T.; Walters, A.; Idoine, N.; Gunn, G.A.; Shaw, R.; Rayner, D. Lithium; British Geological Survey: Nottingham, UK, 2016.

15. Brown, T. Measurement of mineral supply diversity and its importance in assessing risk and criticality. Resour. Policy 2018, 58, 202-218. [CrossRef]

16. Spencer, R.; Hill, L. Specialty Minerals and Metals Industry Overview; Canaccord Genuity: Vancouver, BC, Canada, 2016.

17. Gruber, P.W.; Medina, P.A.; Keoleian, G.A.; Kesler, S.E.; Everson, M.P.; Wallington, T.J. Global lithium availability. J. Ind. Ecol. 2011, 15, 760-775. [CrossRef]

18. Miedema, J.H.; Moll, H.C. Lithium availability in the EU27 for battery-driven vehicles: The impact of recycling and substitution on the confrontation between supply and demand until 2050. Resour. Policy 2013, 38, 204-211. [CrossRef]

19. Lowe, M.; Tokuoka, S.; Trigg, T.; Gereffi, G. Lithium-Ion Batteries for Electric Vehicles: The US Value Chain; Center on Globalization, Governance \& Competitiveness, Duke University Press: Durham, NC, USA, 2010.

20. Notter, D.A.; Gauch, M.; Widmer, R.; Wager, P.; Stamp, A.; Zah, R.; Althaus, H.-J. Contribution of Li-ion batteries to the environmental impact of electric vehicles. Environ. Sci. Tehnol. 2010, 44, 6550-6556. [CrossRef]

21. Martin, G.; Rentsch, L.; Hoeck, M.; Bertau, M. Lithium market research-Global supply, future demand and price development. Energy Storage Mat. 2017, 6, 171-179. [CrossRef]

22. Ballinger, B.; Stringer, M.; Schmeda-Lopez, D.R.; Kefford, B.; Parkinson, B.; Greig, C.; Smart, S. The vulnerability of electric vehicle deployment to critical mineral supply. Appl. Energy 2019, 255, 113844. [CrossRef]

23. Pehlken, A.; Albach, S.; Vogt, T. Is there a resource constraint related to lithium ion batteries in cars? Int. J. Life Cycle Assess. 2017, 22, 40-53. [CrossRef]

24. Lucay, F.A.; Gálvez, E.D.; Salez-Cruz, M.; Cisternas, L.A. Improving milling operation using uncertainty and global sensitivity analyses. Miner. Eng. 2019, 131, 249-261. [CrossRef]

25. Clift, R.; Druckman, A. Taking Stock of Industrial Ecology; Springer: Berlin, Germany, 2016; ISBN 9783319205700.

26. Jaskula, B.W. Lithium, Minerals Yearbook-2015; US Geological Survey: Reston, VA, USA, 2017; pp. 41-44.

27. Müller, E.; Hilty, L.M.; Widmer, R.; Schluep, M.; Faulstich, M. Modeling Metal Stocks and Flows: A Review of Dynamic Material Flow Analysis Methods. Environ. Sci. Technol. 2014. [CrossRef]

28. Glöser, S.; Soulier, M.; Espinoza, L.T.; Faulstich, M. Using Dynamic Stock \& Flow Models for Global and Regional Material and Substance Flow Analysis in the Field of Industrial Ecology: The Example of a Global Copper Flow Model. In Proceedings of the 31st International Conference of the System Dynamics Society, Cambridge, MA, USA, 21-25 July 2013.

29. Emilia, S. Dynamic Modelling of Material Flows and Sustainable Resource Use Case Studies in Regional Metabolism and Space Life Support Systems Emilia Suomalainen; Université de Lausanne: Lausanne, Switzerland, 2012.

30. Gerst, M.; Graedel, T.E. In-Use Stocks of Metals: Status and Implications. Environ. Sci. Technol. $2008,42$. [CrossRef]

31. Hodge, A.; Crowley, B.; Bairstow, H.; Ljubisavljevic, S.; Hamilton, C.; Morton, P.; Kejriwal, D.; May, C.; Diyachkina, P.; South, F.; et al. Global Lithium Report; Macquarie Group Limited: Sydney, Australia, 2016. 
32. Foss, M.M.; Gülen, G.; Tsai, C.-H.; Quijano, D.; Elliott, B. Battery Materials Value Chains; Center for Energy Economics (CEE): Austin, TX, USA, 2015.

33. Helton, J.C.; Oberkampf, W.L. Alternative representations of epistemic uncertainty. Reliab. Eng. Syst. Saf. 2004, 85, 1-10. [CrossRef]

34. Rowe, W.D. Understanding uncertainty. Risk Anal. 1994, 14. [CrossRef]

35. Helton, J.C.; Burmaster, D.E. Treatment of aleatory and epistemic uncertainty in performance assesments for complex systems. Reliab. Eng. Syst. Saf. 1996, 54, 91-94. [CrossRef]

36. Oberkampf, W. Uncertainty quantification using evidence theory. In Proceedings of the Advanced Simulation Computing Workshop, Albuquerque, MN, USA, 22-23 August 2005.

37. Christian, J.; Van Der Sluijs, J.P.; Lajer, A.; Vanrolleghem, P.A. Uncertainty in the environmental modelling process e A framework and guidance. Environ. Model. Softw. 2007, 22, 1543-1556. [CrossRef]

38. Casals Casals, L.; Amante García, B.; Gonzáles Benítez, M. Modelling Li-Ion Battery Aging for Second Life Business Models Lluc Canals Casals Modelling Li-Ion Battery Aging for Second Life Business Models; Universitat Politécnica de Catalunya: Barcelona, Spain, 2016.

39. Richa, K.; Babbitt, C.W.; Gaustad, G.; Wang, X. A future perspective on lithium-ion battery waste flows from electric vehicles. Resour. Conserv. Recycl. 2014, 83, 63-76. [CrossRef]

40. Mohr, S.H.; Mudd, G.M.; Giurco, D. Lithium resources and production: Critical assessment and global projections. Minerals 2012, 2, 65-84. [CrossRef]

41. Morgan, M.G.; Henrion, M. A Guide to Dealing with Uncertainty in Quantitative Risk and Policy Analysis; Cambridge University Press: Cambridge, UK, 2007; ISBN 9780521365420.

42. Brunner, H.; Rechberger, P. Practical Handbook of Material Flow Analysis; Lewis Publishers: Boca Raton, FL, USA, 2005; ISBN 1566706041.

43. Saltelli, A.; Trantola, S.; Campolongo, F.; Ratto, M. Sensitivity Analysis in Practice; Wiley: Hoboken, NJ, USA, 2004; ISBN 0470870931.

44. Lilburne, L.; Tarantola, S. Sensitivity analysis of spatial models. Int. J. Geogr. Inf. Sci. 2009, 23, 151-168. [CrossRef]

45. Saltelli, A.; Annoni, P.; Azzini, I.; Campolongo, F.; Ratto, M.; Tarantola, S. Variance based sensitivity analysis of model output. Design and estimator for the total sensitivity index. Comput. Phys. Commun. 2010, 181, 259-270. [CrossRef]

46. Lucay, F.A.; Lopez-Arenas, T.; Sales-Cruz, M.; Gálvez, E.D.; Cisternas, L.A. Performance Profiles for Benchmarking of Global Sensitivity Analysis Algorithms. Rev. Mex. Ing. Química 2020, 19, 423-444. [CrossRef]

47. Saltelli, A.; Ratto, M.; Andres, T.; Campolongo, F.; Cariboni, J.; Gatelli, D.; Saisana, M.; Tarantola, S. Global Sensitivity Analysis. The Primer; John Wiley \& Sons, Ltd.: Chichester, UK, 2007; ISBN 9780470725184.

48. Grosjean, C.; Herrera, P.; Perrin, M.; Poggi, P. Assessment of world lithium resources and consequences of their geographic distribution on the expected development of the electric vehicle industry. Renew. Sustain. Energy Rev. 2012, 16, 1735-1744. [CrossRef]

49. Wendl, M.; Wietschel, M.; Marscheider-Weidemann, F.; Angerer, I.G. Abschätzung des Künftigen Angebot-Nachfrage-Verhältnisses von Lithium vor dem Hintergrund des Steigenden Verbrauchs in der Elektromobilität; Karlsruhe Institut für Technologie: Karlsruhe, Germany; Fraunhofer-Institut für System-und Innovationsforschung: Karlsruhe, Germany, 2009.

50. Jaskula, B.W. Lithium, Minerals Yearbook-2014; US Geological Survey: Reston, VA, USA, 2016; pp. 41-44.

51. Vikström, H.; Davidsson, S.; Höök, M.; Sonoc, A.; Jeswiet, J.; Idjis, H.; Attias, D.; Bocquet, J.C.; Richet, S. A review of lithium supply and demand and a preliminary investigation of a room temperature method to recycle lithium ion batteries to recover lithium and other materials. Procedia CIRP 2013, 110, 252-266.

(C) 2020 by the authors. Licensee MDPI, Basel, Switzerland. This article is an open access article distributed under the terms and conditions of the Creative Commons Attribution (CC BY) license (http://creativecommons.org/licenses/by/4.0/). 